Special issue of the International Conference on Computational and Experimental Science and Engineering (ICCESEN 2014)

\title{
Influence of Pd Addition of CoCrMo Biomedical Alloys on the Microhardness Behaviour
}

\begin{abstract}
O. Sahin*, S. Uzunoglu And E. Sahin
Mustafa Kemal University, Science and Art Faculty, Micro/Nanomechanic Characterization Laboratory, Hatay 31034, Turkey

CoCrMo alloys are often used as the material for metal artificial joint because of their high corrosion resistance and mechanical properties. In this study CoCrMo alloys having different palladium amount of produced by investment casting method. Scanning electron microscopy, X-ray diffraction method and indentation tests were used to examine the mechanical properties of the alloys. Indentation experiments were carried out using Vickers indenter that the loads range from 0.245 to $9.8 \mathrm{~N}$. The alloys exhibit significant load-dependence (i.e., indentation size effect). Meyer's law, proportional specimen resistance model, and Hays-Kendall model were used to analyze the load dependence of the hardness. As a results for load-independent determination of the CoCrMo alloys, the Hays-Kendall model is found to be more effective than the proportional specimen resistance model and microhardness values decreases with increase of the Pd content.
\end{abstract}

DOI: 10.12693/APhysPolA.128.B-145

PACS: 61.66.Dk, 62.20.- $-\mathrm{x}$

\section{Introduction}

Hardness of a material is defined as its resistance to plastic deformation usually when the indentation test is carried out. The principles of indentation consist of applying a given test load and, subsequently, measuring the dimensions of the residual impression left in the material once the indenter has been withdrawn. Hardness of the load and a parameter representing the area of the residual impression depend on the shape of the indenter and the method employed for the hardness calculation. Hardness of a brittle material as determined by conventional tests (Vickers, Knoop, Berkovich, Rockwell, etc.) is a measure of the material's resistance to deformation, densification displacement and fracture [1].

CoCrMo alloys are one of the most useful alloys for biomedical applications such as dental and orthopedic implants because of their excellent mechanical properties and biocompatibility [2]. Because of these alloys' hard workability and the shape complexity of the prosthesis, this process reduces the high cost of machining operations by producing pieces whose dimensions are close to final ones [3].

It is well known that the main defects present in the as-cast state are: porosity, chemical inhomogeneity, large grain size and a microstructure with hard precipitates in interdendritic zones $[4,5]$. Also due to the casting process, inhomogeneities in carbide morphology and their sizes and distributions may lead to low ductility and low fatigue strength. In order to achieve better performances and to improve their relatively poor ductility the addition of different alloying elements has been intensively studied [6].

*corresponding author; e-mail: sduosman@gmail.com
The as-cast microstructure could also be modified by changing alloying elements. Replacing tungsten by an equal amount of molybdenum improves the ductility, increases the solidification range and changes the morphology of the precipitates by segregation [7]. Therefore, the aim of the present study is investigate the effect of the different palladium amount addition on the microhardness behaviour for the CoCrMo biomedical alloys. According to our best knowledge, our current study is the first to investigate using the Vickers microhardness method on CoCrMo alloys having different amount of Pd.

\section{Experimental procedure}

In this study CoCrMo alloys having different amount of $\mathrm{Pd}$ were produced by investment casting method. Alloys of cobalt, chromium, molybdenum, and palladium were prepared by melting elements (high purity better than $99.9 \%$ ) in the casting furnace under argon atmosphere. The analysed chemical composition of the alloys are given in Table I. Alloys, referred as $1.68 \mathrm{Pd}, 2.70 \mathrm{Pd}$, and $4.33 \mathrm{Pd}$ in this study, were designed by adding $\mathrm{Pd}$ content to a $\mathrm{Co}-29 \mathrm{Cr}-5 \mathrm{Mo}-x \mathrm{Pd}$ (where $x=1.6,2.7$, and 4.33) (all in mass\%). The alloys were melted in the range of $1440-1520^{\circ} \mathrm{C}$. In this system, silica-based crucibles were used for the melt alloys and for eliminating the humidity they were pre-heated to $420^{\circ} \mathrm{C}$. In this system, casting pressure is about 21 to 26 bar. After casting, the investment cooled in air removed and metallic micro components were cleaned. Scanning electron microscopy (SEM) study were performed by a FEI Quanta FEG 250. $\mathrm{X}$-ray diffraction (XRD) (Rigaku Co, Japan) was carried out to analyze the phase compositions in a continuousscanning mode with $\mathrm{Cu} K_{\alpha}$ radiation.

Indentation measurements of the alloys were performed at room temperature using Vickers indenter. Before the indentation tests damage on the surfaces are removed mechanically by grinding 1200 and 2400 grit, and 


\section{TABLE I}

Chemical compositions of the experimental alloys (mass\%).

\begin{tabular}{c|c|c|c|c|c|c}
\hline \hline Alloys & Cr & Mo & Pd & Si & Other & Co \\
\hline $1.68 \mathrm{Pd}$ & 29.50 & 4.90 & 1.68 & 0.98 & 0.69 & bal. \\
$2.70 \mathrm{Pd}$ & 29.19 & 4.87 & 2.70 & 0.97 & 0.68 & bal. \\
$4.33 \mathrm{Pd}$ & 29.00 & 4.80 & 4.33 & 0.96 & 0.67 & bal.
\end{tabular}

then polishing on 6,3 and $1 \mu \mathrm{m}$ diamond lap wheels. Indentation tests loads ranging from 0.245 to $9.8 \mathrm{~N}$ and loading time of $15 \mathrm{~s}$ were used to measure the diagonals of the indentations. In view of the scatter of the microhardness data, the hardness value was a mean of at least six measurements under the same condition.

For the Vickers hardness test, the indenter is a squarebased pyramid for which the angle between the two opposite sides is equal to $136^{\circ}$. By means of simple geometrical considerations, the contact area may be expressed as a function of the diagonal of the indent. The Vickers microhardness $\left(H_{\mathrm{V}}\right)$ is calculated using the following formula:

$$
H_{\mathrm{V}}=1.8544 \frac{P}{d^{2}},
$$

where $P$ is the applied test load in N, $d$ is the average of two indentation diagonal lengths in $\mu \mathrm{m}$, and 1.8544 is a geometrical constant of the diamond pyramid.

\section{Results and discussions}

Before the XRD measurements samples surfaces were polished with $1 \mu \mathrm{m}$ and $0.3 \mu \mathrm{m} \mathrm{Al}_{2} \mathrm{O}_{3}$, and a colloidal $\mathrm{SiO}_{2}$ suspension to form mirror-like surfaces. After polishing, the samples were ultrasonically rinsed in distilled water, alcohol, and acetone. Figure 1 displays the XRD patterns of the examined alloys. As can be seen clearly, the structure of the alloys is formed of the $\gamma-\mathrm{CoCr}$ and $\varepsilon$-CoCr cobalt parent structures. In these phase, $\gamma$ - $\mathrm{CoCr}$ phase has higher concentration. The presence of the $\gamma$ $\mathrm{CoCr}$ phase, with the hexagonal close-packed (hcp) structure, is consistent with the equilibrium $\mathrm{Co} / \mathrm{Cr}$ phase diagram. The presence of the $\gamma$-CoCr phase, existing in the face centered cubic (fcc) structure, is a non-equilibrium transformation during cooling. Also from this figure it can be seen that, as the Pd-doping concentration increases, the (111) and (101) peak intensities decreases, which means the weakening of (111) and (101) preferential growth. This event may be due to the presence of internal stress induced by the adding of Pd during investment casting process, which can alter the energetic balance between different crystal planes orientations and lead to preferred texture in certain conditions [8]. It was also seen from the figure that preferred orientation is slightly changed from (111) to (200) with increasing Pddoping. In addition, the diffraction patterns of the alloys indicate that $\gamma$ phase is predominant phase. The XRD analyses revealed that the $\mathrm{Pd}$ addition effectively stabilizes the $\varepsilon$ phase. It means that higher Pd content sup- presses the formation of $\varepsilon$ phase at room temperature. Similar behaviour also can be seen in the literature of CoCrMo biomedical alloys with $\mathrm{C}$ addition [9].

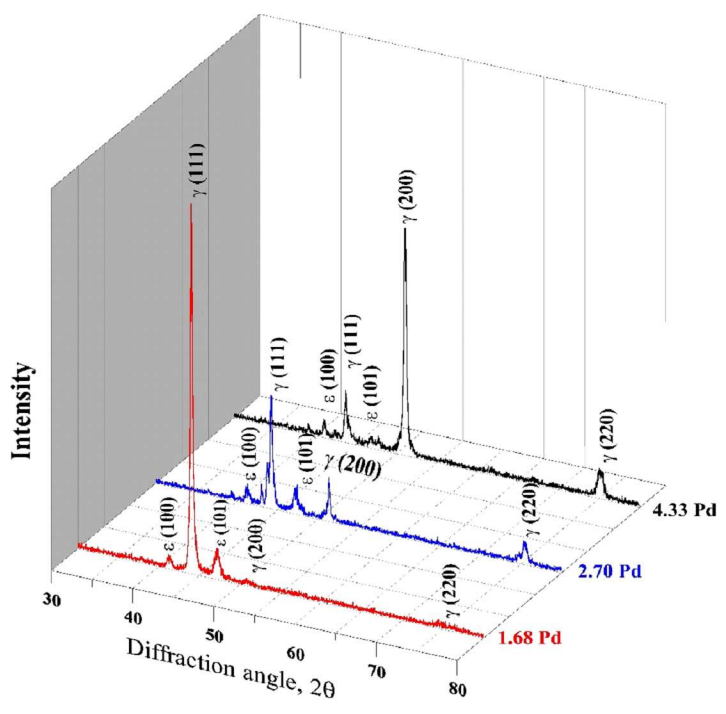

Fig. 1. 3D XRD pattern of CoCrMoPd alloys showing in the presence of $\varepsilon$ and $\gamma$ phases.

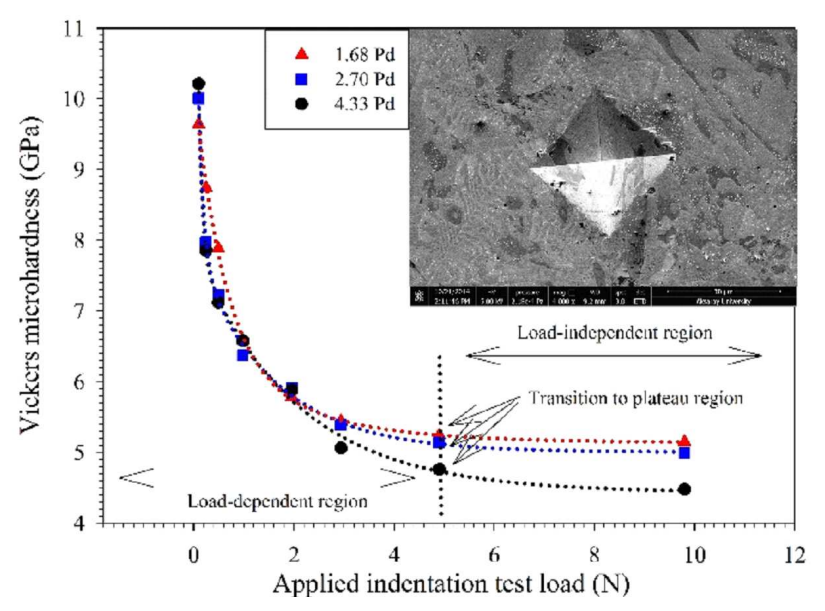

Fig. 2. Vickers microhardness variation as a function of applied indentation test load.

Figure 2 shows the microhardness variation as a function of applied indentation test load. From the figure, one can see that all of the samples microhardness values decrease with increase of applied indentation test load. The curves in the graph show a non-linear behaviour of the microhardness up to certain value of applied test load after which its value tends to achieve saturation. This behaviour is called indentation size effect (ISE) [1, 10-12].

In order to analyze the ISE behavior and to estimate the true microhardness value, several relationships between the applied load and the resulting indentation size have been suggested $[10,11]$. One of those relations is known as Meyer's law and can be expressed as [1, 10, 11]: 


$$
P=A d^{n},
$$

where the power $n$ is the Meyer number, and $A$ is the standard hardness constant. The $A$ and $n$ values in Eq. (2), given in Table II, can be obtained from the $\ln P$ vs. ln $d$ graph (Fig. 3).

\section{TABLE II}

Regression analysis results of experimental data according to Eq. (2).

\begin{tabular}{c|c|c|c|c}
\hline \hline Alloys & $\ln A$ & $A$ & $n$ & $r^{2}$ \\
\hline $1.68 \mathrm{Pd}$ & -2.086 & 0.124 & 1.716 & 0.998 \\
$2.70 \mathrm{Pd}$ & -2.124 & 0.119 & 1.735 & 0.999 \\
$4.33 \mathrm{Pd}$ & -2.089 & 0.124 & 1.698 & 0.999
\end{tabular}

In this study, the $n$ values vary from 1.698 to 1.735 depending on $\mathrm{Pd}$ additive. The decrease of $H_{\mathrm{V}}$ for $n<2$ as the indentation test load increases is in good agreement with other reported results $[1,10]$.

The other model in the literature for analysis of the ISE is proportional resistance model (PSR)[11]. In this model, the indentation diagonal length $d$ is related to indentation test load $P$ as follows:

$$
\left(\frac{P}{d}\right)=a_{1}+a_{2} d
$$

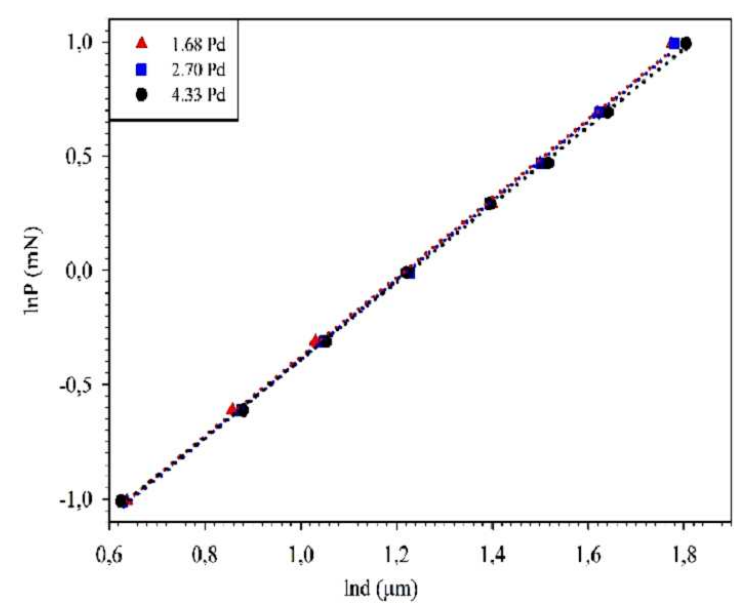

Fig. 3. Plots of $\ln P$ vs. $\ln d$ according to the Meyer law.

where the coefficients $a_{1}$ and $a_{2}$ are the load dependent hardness and the load independent hardness, respectively. Based on the PSR model, for the microindentation test with a Vickers indenter, load-independent microhardness, $H_{\mathrm{PSR}}$, can be determined directly by the relation

$$
H_{\mathrm{PSR}}=1854.4 a_{2}[\mathrm{GPa}] \text {. }
$$

\begin{tabular}{|c|c|c|c|c|c|c|c|c|c|}
\hline Alloys & $\begin{array}{c}a_{1} \\
{\left[\left(\frac{\mathrm{mN}}{\mu \mathrm{m}}\right)^{2}\right]}\end{array}$ & $\begin{array}{c}a_{2} \\
{\left[\left(\frac{\mathrm{mN}}{\mu \mathrm{m}}\right)^{2}\right]}\end{array}$ & $\begin{array}{l}H_{\mathrm{PSR}} \\
{[\mathrm{GPa}]}\end{array}$ & $\begin{array}{c}H_{\mathrm{PSR}} \\
r^{2}\end{array}$ & $\begin{array}{c}H_{\mathrm{LI}} \\
\text { Plateau } \\
\text { value } \\
\text { [GPa] }\end{array}$ & $\begin{array}{c}W \\
{[\mathrm{~N}]}\end{array}$ & $\begin{array}{c}C_{1} \\
{\left[\left(\frac{\mathrm{mN}}{\mu \mathrm{m}}\right)^{2}\right]}\end{array}$ & $\begin{array}{c}H_{\mathrm{HK}} \\
{[\mathrm{GPa}]}\end{array}$ & $\begin{array}{c}H_{\mathrm{HK}} \\
r^{2}\end{array}$ \\
\hline $1.68 \mathrm{Pd}$ & & 2.480 & 598 & 0.997 & 5.105 & .1 & & 5.079 & 0.999 \\
\hline $2.70 \mathrm{Pd}$ & 15.10 & 2.447 & 4.538 & 0.998 & 4.990 & 0.17 & 2.6 & 4.929 & 0.999 \\
\hline $4.33 \mathrm{Pd}$ & 18.81 & 2.157 & 3.999 & 0.993 & 4.477 & 0.254 & 2.380 & 4.413 & 0.99 \\
\hline
\end{tabular}

\section{TABLE III}

Regression analysis of experimental data according to Eq. (3), and Eq. (5).

The best-fit $a_{1}$ and $a_{2}$ parameters and the $H_{\mathrm{PSR}}$ values are listed in Table III. As can be seen from the table, the $H_{\mathrm{PSR}}$ values and the $H_{\mathrm{LI}}$ plateau values do not coincide with each other. Thus, we need the closer examination of the ISE behaviour of the examined alloys. Therefore, in the next section, Hays-Kendall (HK) model was applied to analyze the microhardness data on the alloys.

Hays and Kendall [13] proposed that there exists a minimum applied test load $W$ (test specimen resistance) necessary to initiate plastic deformation and below which only elastic deformation occurs. According to their hypothesis effective indentation load, $P_{\text {eff }}=P_{\max }-W$, is proportional resultant indentation size,

$$
P_{\max }-W=C_{1} d^{2}
$$

where $C_{1}$ is the load-independent hardness constant calculated by HK approach for a given sample. The values of $W$ and $C_{1}$ can be calculated by plotting $P_{\max }$ against $d^{2}$ as shown in Fig. 4. According to the HK approximation, load independent microhardness, $H_{\mathrm{HK}}$, can be calculated as

$$
H_{\mathrm{HK}}=1854.4 C_{1}[\mathrm{GPa}] \text {. }
$$

The fitting parameters $C_{1}, W$ and the calculated values of load independent microhardness $H_{\mathrm{HK}}$ are listed in Table III. Clearly, present data for each sample shows an excellent linear relationship in HK approach and the regression coefficient of each sample is very high, $r>0.999$, implying that Eq. (5) provides a satisfactory description of the indentation data for the samples. In addition, it is revealed that the $W$ values (Table III) are positive for all the samples indicating that the applied load is sufficient to create both the elastic and the plastic deformations.

The load-independent microhardness values estimated by $\mathrm{HK}$ model are very close to the $H_{\mathrm{LI}}$, experimental values plateau region. Based on the closeness of $H_{\mathrm{HK}}$ 


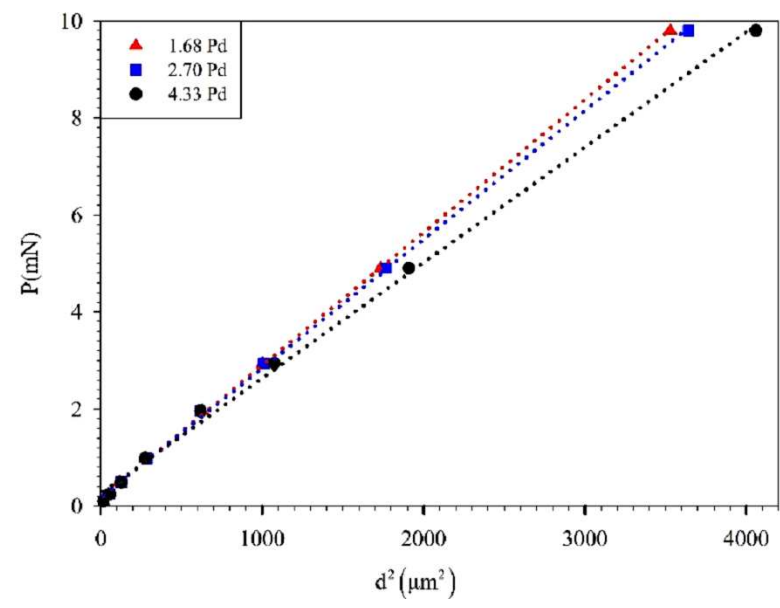

Fig. 4. Variation of the applied load $P_{\max }$ with $d^{2}$ according to Hays-Kendall approach.

and $H_{\mathrm{V}}$, one would speculate that among the PSR and HK models, the HK model has the highest success in accordance with the indentation data. Therefore, it is concluded that the Hays-Kendall approach is suitable for describing our experimental data.

\section{Conclusion}

In this study, we have presented the results of a detailed analysis of microhardness study of Pd-doped CoCrMo biomedical alloys. Microhardness of these alloys was measured by the Vickers indenter. The results can be summarized as follows:

1. Microhardness of the examined samples decreased non-linearly as the applied load increases up to $4.9 \mathrm{~N}$, beyond which the curves tend to attain saturation (nearly plateau) region.

2. This type of variation can be explained by Meyer's relationship up to a certain value of load. However, no useful knowledge of the origin of the observed ISE is gained from this empirical equation.

3. Load-independent hardness value, $H_{\mathrm{PSR}}$, calculated PSR model is obviously below the plateau region. Thus, the PSR model does not accurately describe the ISE behaviour.
4. Indentation size effect behaviour of the $\mathrm{CoCr}$ $\mathrm{MoPd}$ alloys can be explained successfully by using the concept of the HK model. The calculated load-independent hardness values, $H_{\mathrm{HK}}$, are more consistent with that calculated by the PSR model, $H_{\mathrm{PSR}}$.

5. Microhardness values of the $\mathrm{Pd}$-doped $\mathrm{CoCrMo}$ biomedical alloys decreases with increase of the Pd content.

\section{Acknowledgments}

The financial support from research foundation of Mustafa Kemal University (grant no. 12364 and 8481) is also gratefully acknowledged.

\section{References}

[1] H.S. Güder, E. Sahin, O. Sahin, H. Göçmez, C. Duran, H.A. Cetinkara, Acta Phys. Pol. A 120, 1026 (2011).

[2] J. Escobedo, J. Méndez, D. Cortés, J. Gómez, M. Méndez, H. Mancha, Mater. Des. 17, 79 (1996).

[3] J.V. Giacchi, C.N. Morando, O. Fornaroc, H.A. Palacio, Mater. Charact. 62, 53 (2011).

[4] J. Campbell, Castings: The New Metallurgy of Cast Metals, 2nd ed., Elsevier Sci. Technol., Oxford 2003.

[5] D.M. Stefanescu, Science and Engineering of Casting Solidification, 2nd ed., Springer US, USA 2009.

[6] S. Longquan, D.O. Northwood, C. Zhengwang, J. Mater. Sci. 28, 1312 (1993).

[7] L.E. Ramírez, M. Castro, M. Méndez, J. Lacaze, M. Herrrera, G. Lesoult, Scr. Mater. 47, 811 (2002).

[8] K.S. Park, J.K. Park, Acta Mater. 47, 2177 (1999).

[9] S.-H. Lee, E. Takahashi, N. Nomura, A. Chiba, Mater. Trans. 47, 287 (2006).

[10] K. Sangwal, B. Surowska, P. Blaziak, Mater. Chem. Phys. 80, 428 (2003).

[11] J. Gong, H. Miao, Z. Zhao, Z. Guan, Mater. Sci. Eng. A 303, 179 (2001).

[12] O. Şahin, O. Uzun, U. Kölemen, N. Uçar, Mater. Charact. 59, 729 (2008).

[13] C. Hays, E.G. Kendall, Metallography 6, 275 (1973). 